\title{
O PERFIL DOS HOMENS DE NEGÓCIOS NO INTERIOR PAULISTA
}

Eder Carlos Zuccolotto ${ }^{1}$

\begin{abstract}
Resumo: A proposta do presente artigo é a de trabalhar a dimensão do imigrante como homem de negócios e/ou empreendedor, ou ainda agente econômico no interior paulista. Para tanto, tem como principal aporte teórico histórico a análise construída por Florestan Fernandes (2010) sobre o desenvolvimento da revolução burguesa no Brasil, momento que coincide com a implantação, auge e decadência da lavoura cafeeira no oeste paulista (segunda metade do século XIX e primeiras décadas do século XX). Outros autores como José de Souza Martins (1973), Fernando Henrique Cardoso (1969, 1972), Sallum Junior (1982), Agnaldo de Souza Barbosa (2006), João Manoel Cardoso de Mello (1982) e Osvaldo Truzzi (2000) serão utilizados para enriquecer o debate sobre a temática.
\end{abstract}

Palavras chaves: Homens de negócios, Empreendedor, Cafeicultores, Imigrantes, Interior Paulista.

\begin{abstract}
The purpose of this article is to work the size of the immigrant as a businessman and / or entrepreneur, or economic agent in the interior. Therefore, its main theoretical contribution historical analysis built by Florestan Fernandes (2010) on the development of the bourgeois revolution in Brazil, time which coincides with the deployment, peak and decline of coffee plantations in the west of São Paulo (second half of the nineteenth century and early twentieth century). Other authors such as José de Souza Martins (1973), Fernando Henrique Cardoso (1969, 1972), Sallum Junior (1982), Agnaldo de Souza Barbosa (2006), John Manoel Cardoso de Mello (1982) and Osvaldo Truzzi (2000) will be used to enrich the debate on the issue.
\end{abstract}

Keywords: Businessmen, Entrepreneur, Coffee Growers, Immigrants, Interior Paulista.

O surgimento e desenvolvimento de um empreendedorismo comercial e industrial no Brasil somente são possíveis se concebermos o termo "homem de negócios", que não é restrito aos imigrantes; na verdade, foi primeiro associado por Fernandes (2010) aos cafeicultores. Mas, como veremos, nos casos aqui elencados, apesar de contribuírem para o desenvolvimento comercial e industrial, estes não constituíram uma regra geral ao grupo de fazendeiros do café. Já entre os imigrantes, muitos acabaram

Eder Carlos Zuccolotto - Doutorando do Programa de Pós-Graduação em Ciências Sociais da FCLAr/UNESP - Bolsista CNPq. Orientador: Prof. Dr. José Antonio Segatto. E-mail: ederzucco@yahoo.com.br 
se destacando e contribuindo para o desenvolvimento econômico dentro de um perfil empreendedor.

José de Souza Martins, em sua obra O cativeiro da terra (2010, p. 223), ao abordar a questão do café e a gestação do empresário, também chama a atenção para a questão do que ele classifica como habilidade empresarial. Martins (2010, p.223) destaca que, apesar de toda a riqueza dessa temática, aos poucos ela foi se perdendo; frisa também que um dos poucos, senão o único, na sua perspectiva, que trabalhou essa linha foi Warren Dean (1971), que juntou duas linhas de interpretação: a da substituição das importações e da difusão da habilidade na gestão capitalista do capital.

A explanação pioneira sobre o assunto foi realizada, segundo Martins (2010), por Fernando Henrique Cardoso (1972), que tece, em seus estudos, considerações sobre o café e a indústria. No entanto, existe uma diferença entre a visão de Cardoso (1972) e Dean (1971): “[...] a principal diferença é a de que Cardoso analisa os fundamentos históricos e sociais, e as determinações históricas, da consciência empresarial relativa à industrialização [...]" (MARTINS, 2010, p. 223). Enquanto que Dean segue uma linha que valoriza de certa maneira uma ideia de difusão cultural.

Desse modo, torna-se importante perceber quais as influências e contribuições que o café trouxe para o desenvolvimento da indústria e o porquê do seu estudo, a partir do interior paulista.

Durante o século XIX, o movimento da cultura cafeeira deslocandose para o Estado de São Paulo, principalmente para o seu interior, é um momento que coincide com a passagem do trabalho escravo para o trabalho livre (MARTINS, 2010, p. 224). Uma das consequências dessa mudança foi que os fazendeiros passaram a vivenciar novas relações de produção: o trabalho estava agora vinculado como fator de lucratividade calculável do capital. Embora em São Paulo o café tenha, por este motivo, favorecido o desenvolvimento capitalista, em outros lugares, isso não ocorreu com a mesma rapidez.

Localidades como Araraquara, São Carlos, Ribeirão Preto, Franca, Taquaritinga e Rio Claro, esta última localidade estava à margem do que antes se classificava como boca do sertão; cresceram e se desenvolveram com a expansão cafeeira para o Oeste paulista.

O café trouxe, entre outros fatores, para o desenvolvimento destas regiões, elementos importantes: a urbanização, o imigrante e a ferrovia. Cada um deles contribui de maneira marcante para esse desenvolvimento, como veremos um pouco mais detalhadamente no texto. 
Para termos ideia do desenvolvimento dessas regiões, a partir da expansão cafeeira, basta que observemos alguns dados fornecidos por Holloway (1984, p. 33). Segundo o autor, o número de municípios no estado de São Paulo "[...] cresceu de 46 em 1850, para 121 em 1886; 206 em 1920 e 216 em 1934 [...] das 140 novas unidades criadas naquele período $(1886$ - 1934), 118 o foram no planalto ocidental [...]". O planalto ocidental citado pelo estudioso corresponde à região aqui trabalhada como boca do Sertão.

\section{REVOLUÇÃO BURGUESA, CAFEICULTORES E IMIGRANTES}

Ao se abordar a temática do imigrante como possível "homem de negócios" ou ainda como um "pré-burguês" no interior paulista, é crucial uma análise da obra A revolução burguesa no Brasil (2010), de Florestan Fernandes. Nela, o autor traça todo um caminho sobre a formação e desenvolvimento do capitalismo no Brasil, o qual fornece as bases necessárias para o surgimento da chamada "burguesia brasileira" e, consequentemente, de seus homens de negócios.

Antes de falar propriamente da revolução burguesa, Florestan Fernandes (2010, p. 32) faz uma análise interessante sobre as visões que atestam para a existência ou não desta distinção no cenário brasileiro. Para Fernandes (2010, p.32), existem aqueles que afirmam a existência da noção de burguês e burguesia "[...] com a implantação e a expansão da grande lavoura exportadora, como se o senhor de engenho pudesse preencher, de fato, os papéis e as funções socioeconômicas dos agentes que controlavam [...] o fluxo de suas atividades socioeconômicas [...]". Na contramão existiam também aqueles que diziam que ambos não teriam existido no Brasil "[...] como se depreende de uma paisagem em que não aparece nem o castelo nem o Burgo [...]".

Fernando Henrique Cardoso (1972, p. 45) segue esta mesma linha utilizada por Florestan, quando analisa o desenvolvimento do perfil dos empreendedores numa economia subdesenvolvida: "[...] não se pode esperar, por outro lado, que nestas últimas áreas o empreendedor repita, simplesmente, a história dos homens que fizeram o desenvolvimento do capitalismo no período clássico [...]".

Os atores desta revolução burguesa no Brasil são vistos por Cardoso (1972, p. 48) como participantes de uma camada industrial que "[...] concretiza um modo de organização da produção cujas características essenciais estão definidas por um jogo complexo de determinações gerais e 
particulares [...]". O que reforça um caráter fora dos padrões tradicionais na construção de um novo modelo capitalista e, com ele, de uma nova camada social: a dos empreendedores industriais, os quais poderiam, como propõe este estudo, partir de uma matriz ligada aos cafeicultores ou aos imigrantes.

Pensando, primeiramente, nas atividades agrárias, para mais tarde adentrarmos propriamente nas atividades industriais, é interessante percebermos os argumentos, tanto dos que defendem o senhor de engenho, como um precursor do empresário moderno, como daqueles que refutam essa teoria.

Para os críticos, o senhor de engenho não poderia se encaixar dentro deste perfil, pois, "[...] ele ocupa uma posição marginal no processo de mercantilização da produção agrária e não poderia ser o antecessor do empresário moderno [...]" (FERNANDES, 2010, p. 32). Dentro desta perspectiva, é interessante que mesmo o excedente gerado pela produção, não é visto como "lucro", na verdade ela constituía a parte que lhe cabia no circuito global, o qual era resultado dos acordos do pacto colonial.

Fernandes (2010, p.34) promove uma crítica interessante desta visão. Para ele a análise comparativa não cabe no cenário brasileiro, afinal não tivemos aqui um modelo feudal, ou a formação e caracterização de um burgo nos moldes europeus, assim como o burguês nas primeiras relações mestre versus artesão: "[...] o burguês, já surge, no Brasil, como uma entidade especializada, seja na figura do agente artesanal, inserido na rede de mercantilização da produção interna, seja como negociante [...]".

Esses dois modelos de burguês por ele destacados, permaneciam sufocados com o modelo colonial, pois encontravam entraves no escravismo, na dependência da grande lavoura colonial e no estatuto colonial; mesmo assim é interessante notar que o autor diz "sufocadas" e não excluídas ou inexistentes. Ainda destaca que foi com a independência, que a expansão burguesa ganhou condições para sua expansão, contribui para isto o fim do estatuto colonial (pacto colonial).

Para Fernando Henrique Cardoso (1969, p. 188) existe fundamento na perspectiva que considera o surgimento de um processo capitalista durante o período cafeeiro, para ele antes de existir como empresário industrial "[...] o capitalista brasileiro já existia, nesta mesma qualidade de capitalista, como comerciante, como plantador ou como financista, e como tal, capitalista, criava as condições para a implantação do regime capitalista de produção industrial [...]". 
Ao defender que existiam condições para se pensar em uma "revolução burguesa" no Brasil, Fernandes (2010, p.38) ainda deparava-se com a necessidade de esmiuçar este processo. Para o autor, ela não constitui um episódio histórico, mas um fenômeno estrutural, pois "[...] se pode reproduzir de modos variáveis dadas certas condições ou circunstancias, desde que certa sociedade nacional possa absorver o padrão de civilização que a converte numa necessidade histórico-social [...]" (FERNANDES, 2010, p.38). Tal característica pode torna-se mais nítida quando Florestan analisa o estatuto colonial e as mudanças que sua extinção possibilita. No estatuto colonial, ou pacto colonial, as decisões políticas, sociais e econômicas estavam diretamente ligadas aos interesses metropolitanos, ou seja, operavam de fora para dentro da sociedade colonial.

O fim do estatuto colonial significou ganhos para os senhores rurais. Primeiramente, transformaram-se em senhores cidadãos e, nesta perspectiva, suas possibilidades de poder já não eram mais restritas ao domínio senhorial. Além disso, os privilégios sociais que desfrutavam colaboraram para a criação de uma fonte de solidariedade social, que permitiam vantagens nas associações políticas. Assim, o liberalismo ganhou espaço como um fator que garantia os privilégios sociais.

Sobre a utilização do liberalismo pelos senhores, Fernandes (2010, p. 70) faz uma análise que demonstra que este era utilizado de uma maneira peculiar, o que gerava certo antagonismo "[...] as motivações ideológicas do liberalismo eram primariamente econômicas e apenas implicitamente políticas [...] As motivações utópicas do liberalismo, ao inverso, eram diretamente políticas e só secundariamente econômicas [...]".

A independência contribuiu para que antigos padrões fossem alterados ou moldados para atender as necessidades das elites agrárias: "[...] os mecanismos centrais da vida econômica passaram a gravitar em torno de interesses individuais ou coletivos internos e a se organizar a partir deles [...]" (FERNANDES, 2010, p. 83). Ou seja, se antes com o status colonial os senhores eram figuras secundárias, seus interesses estavam subordinados aos interesses metropolitanos; com a independência, eles ganham um papel de destaque, passando a controlar os rumos econômicos. Neste cenário, as relações comerciais ganham mais espaço e os senhores passam a experimentar novas possibilidades.

[...] a reorganização interna do fluxo da renda introduziu o elemento competitivo nas relações econômicas dos 'Senhores rurais', entre si ou com outros agentes econômicos. A partir do momento em que eles podiam inserir-se e participar 
diretamente das diferentes fases internalizáveis da comercialização de produtos exportados, eles se liberavam da expropriação colonial, mas convertiam-se, automaticamente, em puros agentes de transações comerciais [...] (FERNANDES, 2010, p. 91).

É evidente que o processo não ocorreu de forma abrupta. As idas e vindas, os avanços e retrocessos fizeram parte de sua constituição. Fernandes (2010, p. 106) inclusive aponta que as mudanças econômicas contaram com transformações de ordem cultural; este processo fica claro quando ele afirma que "[...] Só com o tempo, graças à expansão do mercado interno e ao aparecimento de condições favoráveis [...], o 'espírito burguês' se libertaria dessas malhas negativas, compostas pelas várias ramificações internas do capitalismo comercial [...]".

Fernandes $(2010$, p. 128) destaca duas figuras importantes dentro desse processo: o fazendeiro de café e o imigrante. $\mathrm{O}$ fazendeiro de café surge como o próprio autor define "[...] uma variante típica do antigo senhor rural [...]", com uma interessante perspectiva: a de "[...] dissociar a fazenda e a riqueza que ela produzia do status senhorial [...]". Quanto ao imigrante, este procurava "[...] a riqueza em si e por si mesma [...]". Os dois possuem muitas diferenças, mas algo em comum: perceberam que existia uma transformação econômica em curso, fruto da ruptura com a antiga ordem senhorial. Nesse cenário, o fazendeiro aceitou e identificou-se com a dimensão burguesa que se apresentava; já o imigrante, como bem assinala o autor, como estava fora do contexto do tradicionalismo, acaba sendo impelido ao processo por interesses de teor espoliativo, extorsivo ou especulativo.

Inicialmente, os fazendeiros ainda estavam presos às concepções dos antigos senhores rurais. No entanto, o mercado externo forçou que a classe reconsiderasse seus investimentos na grande lavoura, as bases materiais (escravismo) e sociais (patrimonialismo), já que não conseguiam sustentar seus padrões de vida. No final do século XIX, passaram a "[...] repudiar o próprio status senhorial, para salvar-se, através do 'elemento burguês' [...] (FERNANDES, 2010, p. 130)". Interessante ressaltar que este processo era inevitável; aos fazendeiros que se negaram a seguir por ele, e mantiveram-se fiéis aos antigos modelos acabaram por facilitar sua ruína.

É o caso dos fazendeiros de café do Vale do Paraíba, que se recusavam a perceber, por exemplo, o esgotamento das relações escravistas na produção, apesar de as velhas fazendas de café do Vale ainda produzirem lucros, tanto elas como o açúcar do Nordeste "[...] eram explorados nos moldes dos latifúndios escravocratas [...] possuíam, contudo, muitas carac- 
terísticas que, segundo suponho, impediam o pleno desenvolvimento de formas propriamente capitalistas de produção [...]" (CARDOSO, 1969, p. 189).

A situação desses fazendeiros poderia ser resumida da seguinte maneira: "[...] O senhor de escravo, por sua vontade e por suas mãos, escravizava-se ao escravo e à ordem social que se fundara na escravidão, condenando-se a desaparecer quando esta fosse extinta [...]" (FERNANDES, 2010, p. 133).

Em contrapartida, alguns fazendeiros do Oeste paulista davam sinais de que a modificação no trato com a produção se fazia necessária. Tanto que muitos deles já adotavam, em suas propriedades, uma mescla de trabalhadores livres com trabalhadores escravos, além de investirem no aperfeiçoamento de técnicas agrícolas, modernização de transportes e separação do lar senhorial com a unidade de produção. Fernandes (2010, p. 136) identifica que dentre todas as transformações, do ponto de vista econômico, que estavam ocorrendo, uma em particular chamava mais a atenção: o estipêndio do status senhorial, que deixaria de ser retirado do excedente da grande lavoura "[...] outras fontes de renda, vinculadas ao setor urbano, passaram a contribuir para o financiamento dos diversos desdobramentos econômicos, sociais e principalmente políticos [...]".

A importância das fazendas do Oeste Paulista também é reconhecida na análise de Cardoso (1969, p. 189) “[...] Nelas ou graças a elas realizaram-se historicamente as condições básicas que antecedem o desenvolvimento industrial capitalista [...]".

Fernandes (2010, p.136) assinala ainda que a própria fazenda sofrera uma importante transformação quanto a sua finalidade para os fazendeiros: “[...] a fazenda, para ele, não é fonte de status, mas de riqueza. Devia dar lucro acima de tudo. Nesse caso, ele não se sujeitava ao estilo de vida isolado e circunscrito do antigo "barão do café' que morava na sede da fazenda [...]". É claro que essa realidade não era totalmente compartilhada por todos os fazendeiros do café, mas, à medida que as relações econômicas tornavam-se mais dinâmicas, os cafeicultores que obtiveram maior êxito econômico estavam mais próximos deste perfil de homens de negócios, como bem ilustra o autor "[...] todavia, esse pequeno número deu colorido e intensidade aos homens que construíram os alicerces da economia moderna no Brasil [...]" (2010, p. 138).

Fernandes (2010, p. 139) distingue dois tipos de personalidade presentes nos fazendeiros de café: "coronéis" ou "homens de negócios". Como coronel, "[...] já era o antípoda do senhor agrário. Afirmava-se como este, 
através do poder político gerado por sua situação econômica. No entanto, despojado do domínio [...] ele se via privado das compensações, da segurança e da autoridade do status senhorial [...]". Nosso maior interesse está no outro tipo de personalidade que se forma, a do fazendeiro como "homem de negócios", que destacamos a seguir.

Dentro do perfil de homens de negócios, os fazendeiros de café assumiram uma postura diferente: passaram a ocupar-se menos com os problemas financeiros e comerciais da fazenda. Para tanto, delegaram essa incumbência para subalternos e somente envolviam-se com essas questões em momentos críticos; "[...] portanto, ele [fazendeiro] encaixava a fazenda na conexão econômica a que ela devia pertencer depois que ela evoluíra para o modelo de plantação comercial típica em regime de trabalho livre [...]" (FERNANDES, 2010, p. 141). Vale destacar ainda que, neste novo perfil, o cafeicultor assumia uma posição estratégica, em que o excedente ganho com a lavoura não se destinava apenas a ser aplicado nela (lavoura), mas também fora dela.

Cardoso (1969, p. 191) complementa bem a análise de Fernandes (2010) ao descrever este novo tipo de fazendeiro.

O fazendeiro de café, nestas condições tornava-se um empreendedor capitalista. Absenteísta, passou a gerir a propriedade rural através de administradores e capatazes, ocupando-se mais com a aplicação e o rendimento do capital do que com a administração direta do trabalho. Habitante da cidade, possuía a mente mais aberta às inovações tecnológicas e ao espírito de racionalização da empresa do que seus antecessores e, muitas vezes, antepassados, do período cafeeiro do Vale do Paraíba

Da mesma forma como Fernandes e Cardoso, Sallum Junior (1982, p.246) também cita as modificações e o crescimento das funções dentro das fazendas de café. Para o autor, à medida que aumentava a massa do capital produtivo "[...] as funções diretivas do capital eram delegadas pelo fazendeiro a trabalhadores assalariados, concentrando-se ele nas funções do capital, não vinculadas ao processo de produção imediata [...]”.

Os cafeicultores carregavam consigo, pensando nessa nova perspectiva, uma mescla do novo, representado pelo fato de serem "homens de negócios", e do tradicional, pois mantinham sua posição de proprietários rurais. Fernandes (2010, p. 142) identifica que esse momento "[...] infundia certa dignidade e grandeza às suas funções de 'homens de negócios', pois sendo também fazendeiro, ele não era um 'homem de negócios' qual- 
quer: tinha atrás de si a auréola, real ou imaginária, da "tradição de família' [...]". É importante dizer ainda que seria este tipo de proprietário rural que esteve presente na implantação do regime republicano, ele foi “[...] o principal agente humano 'ativo' da Revolução burguesa. Ele lhe conferiu o parco e fluído sentido político que esta teve, ao optar pela república e pela liberal democracia [...]".

Para Cardoso (1969, p. 190) a contribuição destes "novos agentes" da economia ganha impulso, sobretudo, com a abolição da escravatura "[...] A nova fazenda de café do Oeste Paulista, ao contrário, ganhou impulso no período de declínio da escravatura, cujo golpe decisivo havia sido desferido pela proibição do tráfico negreiro em 1850 [...]". O fazendeiro paulista passa então a importar mão-de-obra livre, alguns chegam inclusive a engrossar o quadro de abolicionistas, desta maneira "[...] Perdia sua condição de senhor para tornar-se um empresário capitalista [...]".

João Manuel Cardoso de Mello (1998, p. 99) avança ainda mais ao interpretar que "[...] a burguesia cafeeira foi a matriz social da burguesia industrial [...] o capital industrial nasceu como desdobramento do capital cafeeiro empregado, tanto no núcleo produtivo do complexo exportador $[. .$.$] quanto em seu segmento urbano [...]".$

O fazendeiro "homem de negócio" reveste-se, como relata Fernandes (2010, p. 144), de uma "mentalidade econômica tipicamente racional". Mentalidade essa que contribuiu para modificar os fatores que configuravam a estrutura da situação de mercado e "[...] o ápice desse processo foi atingido pela fundação de novos bancos [...] mas ele se desenrolara, de forma latente, desde o fim do século XIX, e tomara alento com as primeiras medidas de 'defesa do café [...]" (2010, p. 145-146).

$\mathrm{Na}$ esteira do pensamento crítico de Fernandes, Martins (2010, p.215) classifica as mudanças como "transformações das seções bancárias". Em sua visão, o desempenho do papel bancário, nas últimas décadas do século XIX, coube a comerciantes e fazendeiros abonados. Ainda ressalta que não podemos esquecer de que as casas comissárias de café tinham essa função, o que se comprova pelo número considerável de capitalistas que apareciam nos almanaques paulistas do século XIX, e que não deveriam ser deixados de lado. $\mathrm{O}$ autor também chama atenção para o fato de que o surgimento destas instituições de crédito com o nome de banco, não poderiam ser classificadas como o início do sistema de crédito, mas sim como parte de seu desenvolvimento (MARTINS, 2010, p. 215).

Esse desenvolvimento pode ser notado por meio das análises que Martins (2010, p.225) faz acerca da experiência que esse grupo (de co- 
merciantes e fazendeiros) herda ao dedicar-se às atividades bancárias. Tal prática habilitou-os a descobrir que a rentabilidade real do capital decorria do uso do capital pelo capital. A utilização capitalista do capital, na visão de Martins (2010, p.225), estava em uma dimensão maior do que apenas emprestar dinheiro a juros "[...] numa certa medida, isso teria permitido o aparecimento de uma atividade empresarial "pura' [...]".

Outro ponto que chama atenção está relacionado ao investimento que alguns cafeicultores realizam nas atividades industriais, segundo Mello (1982, p. 99) o final do século XIX marca boa parte dos investimentos nesta área "[...] ocorreu que entre 1890 e 1894, a taxa de acumulação financeira sobrepassou, em muito, a taxa de acumulação produtiva. Era suficiente, portanto, que os projetos industriais assegurassem [...] uma taxa de rentabilidade esperada positiva [...]".

Para Mello (1982, p. 101) o complexo cafeeiro foi responsável por um processo de acumulação de capital-dinheiro "[...] que se transformou em capital industrial e criou condições necessárias a essa transformação: uma oferta abundante no mercado de trabalho e uma capacidade de importar alimentos, meios de produção e bens de consumo e capitais [...]".

Outra contribuição realizada pelos fazendeiros de café seria a mãode-obra livre, e não apenas aquela destinada ao trabalho rural, segundo Mello (1982, p. 101) "[...] a existência de trabalhadores livres a disposição do capital industrial deveu-se à imigração em massa, que supriu as necessidades do núcleo produtivo e do segmento urbano do complexo exportador [...]".

Percebe-se assim que o novo tipo de fazendeiro, com perfil de "homem de negócios", não fica subordinado a ações que antes vinham do governo, como no período colonial, agora ele possuía uma maior participação nas decisões políticas e econômicas.

Antes de adentrarmos para a questão dos imigrantes, dentro deste processo de "empreendedores" no decorrer de uma revolução burguesa, vale ressaltar que apesar de reconhecer a existência dessa revolução, alguns autores questionam o período inicial desse processo. É o caso daqueles que identificam a revolução burguesa situada a partir da crise de 1929.

José de Souza Martins (2010, p.210) faz uma observação muito interessante sobre esse argumento. Reconhece que a ruralização e os interesses agrícolas prevalecem, pois durante a "República Velha" o governo e 
suas ações se fazem dependentes dos interesses dos cafeicultores. Apesar disso, Martins considera essa tendência (de forte vínculo do governo a elite cafeeira) simplista, pois situa o processo que leva a revolução burguesa iniciando-se a partir de 1929, com o enfraquecimento dos cafeicultores:

\footnotetext{
Os autores desta tendência de compreensão do tema forçam o uso, descabido, de um esquema interpretativo que toma a crise de 1929 como divisora numa suposta e equivocada, porque simplista, passagem de pré capitalismo a capitalismo, e a Revolução de Outubro de 1930 como se fosse a revolução burguesa de que o Brasil carecia para libertar-se de seus supostos bloqueios feudais. (MARTINS, 2010, p. 210)
}

A análise de Martins é reforçada pelo trabalho de Castro (1969), citado em obra de João Manuel Cardoso de Mello (1998, p. 90), o qual destaca que "[...] a crise de 1929 não significa, em absoluto o inicio da industrialização, mas sim sua aceleração [...]".

Avançando ainda mais para estas questões relativas crise de 1929, englobando também as desvalorizações das taxas de cambio e as guerras mundiais, Cardoso $(1969$, p. 195), considera que estas condições econômicas tiveram contribuição no processo de industrialização, mas não são suficientes para explicar este processo no Brasil "[...] O quadro explicativo mais amplo só se completa quando se considera que anteriormente a economia brasileira sofrera modificações que diziam respeito ao próprio regime social de produção [...]".

Passando para a perspectiva do imigrante, como homem de negócios, cabe ressaltar que o próprio Florestan Fernandes (2010, p. 153) identifica certa dificuldade em abordá-la, devido à grande diversificação das correntes migratórias e dos fatos que envolvem sua incorporação às economias internas. No entanto, para nosso processo investigativo, nesta dissertação, serão abordados certos elementos da situação dos imigrantes presentes na "[...] realização de suas carreiras ou nas influências construtivas que exerceram, seja para eliminar e aperfeiçoar, seja para substituir certos padrões obsoletos de vida econômica [...]". De imediato, a presença do imigrante já representou um avanço na esfera capitalista comercial e financeira, gerando reflexos principalmente no mercado interno.

A presença do trabalhador europeu não representou apenas a substituição do antigo modelo de trabalho escravo, pelo de trabalho livre. Lógico que, com a introdução em larga escala do trabalho livre, o mercado interno sofreu uma consequente expansão; todavia, o imigrante não ficou 
restrito apenas a ser mais um braço para as lavouras, muitos acabaram constituindo-se em "homens de negócios". Sendo que a própria visão do estrangeiro de modo geral "[...] fazia parte da sua perspectiva e do seu cálculo econômico acumular riqueza em forma monetária. Considerações de status possuíam para ele escassa significação [...]" (FERNANDES, 2010, p. 156).

Participar dos caminhos que levavam à acumulação de capital não foi uma tarefa das mais fáceis, naturalmente que os imigrantes percorreram as trilhas mais duras e penosas. No entanto, o que poderia se constituir em barreira para sua inserção neste quadro, pelo fato de serem relegados pelos membros das elites senhoriais, representou um benefício a eles. Poderiam, pois, fechar-se em pequenos grupos, que acabavam por abster-se de interagir moralmente com os costumes e os valores da nova sociedade: "[...] liberdade para atingir seus fins, rompendo com o código ético a que teria que responder em sua sociedade nacional e não respondendo ao código ético das camadas senhoriais da sociedade brasileira [...]" (FERNADES, 2010, p. 158).

Ao longo dos anos, alguns imigrantes conseguiram participar mais ativamente da vida econômica. Contribui para isso a capacidade dessa nova classe de "[...] explorar as oportunidades econômicas abertas pela mobilidade horizontal e vertical, com tamanha versatilidade ocupacional ou econômica [...]" (FERNANDES, 2010, p. 160). Fernandes chama atenção também para o fato de que, apesar de ainda estar longe do topo, o imigrante já se configurava como um agente econômico da concentração de capital comercial e, aos poucos, ia assumindo os papéis econômicos emergentes de uma economia de mercado, que passava por um período de consolidação.

Mesmo nas fazendas os imigrantes conseguiram aos poucos algumas conquistas importantes, como a produção de produtos de subsistências; com o tempo está produção passou a gerar até algum excedente "[...] este excedente era vendido nos núcleos urbanos, aumentando, pois, a capacidade de consumo do imigrante [...]" com o tempo alguns imigrantes aumentavam "[...] suas possibilidades de escapar da vida agrícola graças as economias acumuladas, que podiam, então, ser invertidas em pequenos negócios nas vilas e cidades [...]" (CARDOSO, 1969, p. 192).

Cardoso (1972, p.49) afirma que esse período de consolidação também está inserido dentro do processo que leva à formação da ordem industrial-capitalista no Brasil. Fase que contribuiu para a constituição da camada empresarial, segundo o autor: "[...] tentamos compreender a ação 
empresarial tanto como resultado de uma estrutura determinada do mercado e da sociedade, quanto como variável que interfere na gênese deste mercado e sociedade [...]".

Além do mais, o imigrante conhecia as possibilidades do mercado interno, quais as áreas que poderiam ser atacadas segundo um novo estilo. Para tanto, mobilizou capitais e promoveu arranjos comerciais, além de "[...] introduzir, na comercialização de produtos agropecuários, destinados ao consumo ou à produção industrial, técnicas empregadas na Europa, onde o capital comercial procedeu à concentração da produção artesanal [...]" (FERNANDES, 2010, p. 161). Enveredar pelo ramo industrial seria um salto muito grande, mas, diante da perspectiva apresentada e amparados pelo crédito e confiança, os imigrantes puderam trilhar por esse caminho.

Fernandes $(2010$, p. 161) confere uma importância muito grande aos feitos obtidos pelos imigrantes neste período de desbravamento da economia. Para ele, o imigrante tornou-se o principal agente econômico, que contribuiu para a substituição do modelo que privilegiava as importações. Foi um agente privilegiado nas fases iniciais da concentração industrial, sendo inclusive considerado como um "herói da industrialização", que segundo Fernandes $(2010$, p. 161) representou um marco na transformação estrutural que "[...] tornou a Revolução Burguesa uma realidade histórica no Brasil [...]".

O imigrante conseguiu tirar proveito de situações, como por exemplo, a instalação de casas bancárias e agências financeiras estrangeiras; embora enfrentasse certas dificuldades, principalmente pelo perfil de acumulação ainda alicerçado em um tipo estamental de capital, em que se vê a circulação de renda, vinculada a uma sociedade senhorial.

Assim como dos fazendeiros que adotavam o estilo de "homens de negócios", Fernandes (2010, p. 162) assinala a importância desta ligação relacionada ao trabalhador estrangeiro: "[...] o imigrante concentrou sua ação econômica em áreas que eram vitais para o aparecimento ou fortalecimento das referidas conexões [...]". O que, de certo modo, contribuiu ainda para expandir e diferenciar a rede de estabelecimentos comerciais e para fortalecer as relações de comercialização e produção interna.

As pretensões dos imigrantes dentro desse processo, segundo Fernandes (2010, p. 166) assumem um caráter de tendências imediatistas. Ao tratar novamente o imigrante como "o principal agente econômico" do processo de formação e expansão do novo regime, observa que essa nova classe não tinha razões emocionais, materiais e morais que a impelisse a 
projetos econômicos de longa duração. Fernandes (2010, p.167) também realiza uma ressalva para essa perspectiva: afirma que apesar de se preocuparem com o futuro, os imigrantes tiveram que lutar contra a lógica estabelecida dentro daquele sistema de mercado ainda com traços senhoriais. Tal ação exigia que ele (imigrante) se afastasse dos elementos reguladores da ética capitalista, o que o obrigava a posturas e ações de caráter imediatista (FERNANDES, 2010, p. 167).

Convém ressaltar que o caminho que o imigrante percorreu para alcançar este posto de agente privilegiado da economia, foi alcançado a partir do preenchimento de três papéis construtivos da economia monetária:

[...] primeiro coube-lhe uma função primordial para a constituição de uma economia capitalista: a de constituir o agente original do trabalho livre [...] segundo malgrado sua condição de inicial de equivalente humano do escravo, o imigrante logo se erigiu no único elemento que possuía expressão monetária e poder aquisitivo real [...] terceiro, o imigrante tanto concorreu para intensificar o desenvolvimento interno do capitalismo comercial e financeiro, quanto ocupou uma posição central na canalização socialmente construtiva de suas influências dinâmicas, que faziam pressão sobre a diferenciação e a intensificação da produção destinada ao consumo interno [...] (FERNANDES, 2010, p. 169).

Alguns fatores que poderiam ajudar a entender o impacto da imigração sobre a expansão interna do capitalismo são levantados por Fernandes (2010, p. 170). Num primeiro momento, o autor discorre sobre a questão da tradição cultural, alertando que tal fato poderia se constituir como fonte de bloqueio à ação econômica e racional do imigrante; todavia nem sempre provinham de áreas em que o capitalismo comercial e industrial estavam intensamente desenvolvidos. Na verdade, a intenção de imigrar estava atrelada às insatisfações econômicas e sociais; seu papel passa então a ser muito interessante, pois se tornam agentes do processo de transformação de uma "ordem tradicional" para uma "ordem capitalista". Tal processo viria a ocorrer em suas comunidades de origem, mas acabam integrando-o em solo brasileiro.

Em segundo lugar, Fernandes (2010, p. 171) identifica as questões de adaptação em que o cenário que o imigrante vivencia de desagregação da ordem escravocrata e senhorial não estavam relacionados a fatores psicológicos, mas sim a fatores psicossociais. Nesse cenário de mudança, o estrangeiro soube se aproveitar das oportunidades econômicas emergentes 
(alteração dos padrões de consumo, diferenciação do comércio e aumento do mercado interno).

Por último, Fernandes (2010, p. 172-173) sinaliza para a emergência dos imigrantes constituírem papéis econômicos novos e promoverem certos ajustamentos sociais. Eles não podiam competir com os senhores agrários ou com os fazendeiros (tanto "coronéis" como "homens de negócios"); contudo, possuíam um papel decisivo nesta nova ordem e cada vez mais o mercado interno e externo exigia a criação de novos papéis. O surgimento dos novos atores, que atendiam pelo nome de empreendedores, é importante também pelo local de atuação: a nascente indústria brasileira.

Para Cardoso (1972, p. 50), no entanto, não bastava perceber o processo de industrialização apenas dos ângulos sociológico e econômico. Era preciso que esses fossem completados por meio de uma análise que destacasse as características sociais da camada social empresarial brasileira, "[...] uma vez que a industrialização se processou em termos do sistema capitalista de organização econômica, no qual os empreendedores exercem parte do impulso dinâmico no sistema produtivo [...]" (CARDOSO, 1972, p.50).

A importância desse novo cenário que nasce pode ser percebido quando Cardoso (1972, p. 60) frisa que o processo de industrialização é o responsável pela transformação das antigas culturas, que segundo ele são afetadas em cinco setores fundamentais: sistema familiar, estrutura de classe e raça, valorizações éticas e religiosas, ordenação jurídica e conceito de Estado-Nação.

Voltando na figura do imigrante como homem de negócios, José de Souza Martins (2010, p.252) caracteriza que é a partir de 1890 que o trabalhador estrangeiro, principalmente o imigrante italiano, adentrou para o mundo dos grandes negócios; período que coincide com a entrada mais numerosa de imigrantes no país. Martins destaca ainda a presença desses imigrantes, neste primeiro momento, como ligados à atividades comerciais e bancárias:

[...] entre 1891 e 1905 foram registrados na junta comercial de São Paulo 42 novos bancos constituídos no período [...] desses novos bancos, 22 eram de propriedade de imigrantes italianos radicados no Brasil. Entre 1899 e 1905 foram fundados 23 novos bancos, dos quais 22 eram os referidos bancos de imigrantes italianos. Além disso, havia acionistas italianos em pelo menos três bancos de maioria brasileira, dois dos quais poderosos estabelecimentos de famílias tradicionais de São Paulo (MARTINS, 2010, p. 252). 
O início do século XX é apontado por Martins (2010, p.254) como o momento de crescimento do imigrante como industrial. Fato que se confirma por neste período já existir em São Paulo 36 indústrias de imigrantes italianos na cidade, sendo a maioria na capital, onde praticamente imperava o padrão de organização da grande indústria. Essas indústrias reuniam em seus quadros mais de 3.500 operários; isso sem contar as pequenas oficinas de trabalhos, pequenas e médias fábricas e essas mesmas indústrias e oficinas que pertenciam a outros imigrantes.

\section{ASCENSÃO DOS IMIGRANTES NO INTERIOR PAULISTA}

Os primeiros incentivos, para o desenvolvimento dos principais centros cafeicultores do Oeste paulista, foram realizadas por iniciativa de alguns grupos de fazendeiros do café. Tal fato vai ao encontro dos argumentos propostos por Florestan Fernandes (2010), sobre o desenvolvimento inicial da Revolução Burguesa no Brasil. Para termos uma visão mais geral dessa ação, basta que observemos o trabalho de Holloway (1984, p.39), em que o autor aborda, por exemplo, o esforço dos cafeicultores na construção de um trecho de quatrocentos quilômetros que facilitariam o escoamento do café no trajeto compreendido entre Ribeirão Preto e Santos: "[...] A estrada de ferro mogiana, organizada e financiada por fazendeiros da área, começou a ser construída em Campinas, em 1874, e alcançou Ribeirão Preto uma década mais tarde [...]".

Vale ressaltar ainda que tal esforço para dinamizar o escoamento da produção, tinha uma forte motivação econômica, a qual estava em diminuir o tempo e os gastos, que eram mutuamente mais elevados com as tropas de mulas. Desse modo, a ferrovia representou não apenas a modernização, mas o desbravamento de regiões pouco aproveitadas do interior paulista, como é o caso da região de Araraquara, que em 1895 teve o início da construção de sua estrada de ferro (conhecida como Araraquarense).

Assim, a região expandiu-se: "[...] possuía apenas três municípios em 1886, mas o número cresceu para 24 em 1920 e 36 em 1934. A Araraquarense incluiu novas áreas de desenvolvimento, tanto na década de 1920 como mais tarde [...]" (HOLLOWAY, 1984, p. 41). A ferrovia servia aos interesses de dinamizar a produção do café, diminuindo perdas e tempo de transporte, mas não ficou restrita a isso, ela também promovia o transporte de pessoas e de outros bens; além do desbravamento de novas áreas, ou seja, acabou se tornando um importante instrumento de desenvolvimento. 
Outra importante realização dos cafeicultores foi o desenvolvimento dos núcleos urbanos "[...] numa economia deste tipo é fácil de compreender que os núcleos urbanos passavam a exercer funções econômicas importantes [...] toda a distribuição das mercadorias necessárias ao consumo das fazendas faziam-se através das cidades [...]" (CARDOSO, 1969, p. 192).

Torna-se, portanto evidente que as novas condições de exploração do café colaboraram tanto para a utilização da mão-de-obra livre, quanto para um maior desenvolvimento do mercado consumidor, ou seja, "[...] instigaram nos mais audazes dentre os fazendeiros, comerciantes ou antigos imigrantes que passaram a negociar ou trabalhar em oficinas nos núcleos urbanos, o espírito de empresa [...]" (CARDOSO, 1969, p. 193).

Infelizmente, grande parte dos cafeicultores possuíam uma visão comercial muito restrita e, mesmo aqueles que pertenciam aos grupos mais inovadores acabavam muitas vezes retrocedendo em algumas concepções e políticas. É o caso da visão que tinham em relação aos imigrantes. Para os fazendeiros do café, os trabalhadores estrangeiros nada mais eram - como bem frisou Holloway (1984) - "braços para o café"; tal fato pode ser claramente percebido quando observamos a posição do governo e dos cafeicultores em relação à política imigratória: "[...] Os fazendeiros e o governo consideravam o trabalho na indústria, comércio e outros serviços, e mesmo ocupações agrícolas que não a produção do café, prejudiciais ao objetivo básico [...]" (1984, p. 61).

O despreparo de muitos cafeicultores com a nova ordem, onde o trabalho livre do imigrante predominava, evidenciava ainda mais a falta de preparo que muitos fazendeiros tinham em administrar uma nova realidade econômica. Holoway (1984, p.62) mostra um claro exemplo disso no fato de que eles (cafeicultores) não tinham muita noção de como remunerar os imigrantes, e de quanto estes estariam dispostos a assumir nos riscos de produção. Políticas e práticas como as do colonato, parceria, armazém e "caderneta" de gastos, são apenas alguns exemplos de mecanismos que ainda estavam afastados do modelo assalariado.

As dificuldades de ajustamento na relação entre fazendeiros e imigrantes também são destacadas por Sallum Junior (1982, p. 78). Existia, segundo o autor, uma dificuldade de os fazendeiros perceberem que agora lidavam com trabalhadores, que pelo menos no plano jurídico, seriam seus iguais " [...] Os regulamentos das fazendas eram extremamente reveladores desse desajustamento [...] neles se materializavam características da sociedade brasileira da época, pouco compatíveis com a liberdade [...]" (SALLUM JÚNIOR, 1982, p.78). 
A estrutura legal da época também é ressaltada por Sallum Junior (1982, p. 79) como adequada aos interesses dos cafeicultores. Vigorava na época ( $2^{a}$ metade do século XIX), uma legislação denominada de Ordenações Filipinas, que qualificava os imigrantes como "sócios" dos fazendeiros. Na verdade, o interesse desta "sociedade" estava no fato de que desse modo os fazendeiros poderiam "[...] legalmente, obrigar os parceiros recalcitrantes a cumprir os contratos e os regulamentos sobre pena de prisão, inclusive com trabalhos forçados [...]".

As dificuldades que ocorriam, em virtude do endividamento dos imigrantes, foram resolvidas definitivamente a partir de 1884, quando o governo paulista toma as rédeas e passa ele a subsidiar totalmente a imigração. Sallum Junior (1982, p. 90) aponta que tal decisão acaba por ser fundamental, não apenas para os imigrantes, mas para os próprios fazendeiros do Oeste paulista, que necessitavam de trabalhadores em larga escala para os cafezais.

Com o tempo, graças a sua luta e favorecidos por políticas como as do governo paulista, os imigrantes foram vencendo tais barreiras e passaram a ocupar papéis de destaque no desenvolvimento econômico do Oeste paulista. Como bem frisou Florestan Fernandes (2010), eles representaram um importante marco no desenvolvimento da Revolução Burguesa, seja na cidade, ou no campo, passaram a ter um papel de destaque. Holloway (1984, p. 212) afirma que no campo "[...] alguns estrangeiros residentes, bem sucedidos no comércio ou na indústria, adquiriram propriedades rurais, porém, muitos dos imigrantes que se tornaram proprietários de fazendas operadas por trabalho familiar começaram provavelmente como colonos [...]".

São exemplos de imigrantes que obtiveram grande sucesso como proprietários rurais: Francisco Schimidt, Geremia Lunardelli e Miguel Rinaldi. Holloway (1984) destaca que os dois primeiros casos são excepcionais, chegando a receber inclusive o título de Barões do café, fugindo inclusive às características presentes nos demais casos de imigrantes bem sucedidos com propriedades rurais. A região que mais se destacou neste quesito foi a zona Araraquarense; era a região que mais tinha fazendas em propriedade de italianos no estado de São Paulo. Os dados sobre a ocupação de propriedades rurais por imigrantes, principalmente na região de Araraquara impressionam:

[...] Em trinta e sete, dos noventa e sete municípios do planalto ocidental, os imigrantes eram donos de 30 por cento ou mais das propriedades rurais enumeradas em 1905. Em cinco municípios, os proprietários estrangeiros estavam em maioria, com 50 por cento ou mais de todas as propriedades. $\mathrm{O}$ caso mais extremo 
de penetração estrangeira foi o município de Taquaritinga, localizado a noroeste de Araraquara, no que ainda era uma área de fronteira, em 1905. Do total de 352 propriedades rurais em Taquaritinga, 171 (49 por cento) pertenciam a italianos [...] Taquaritinga era uma área de pequenas propriedades, em mãos de italianos por excelência [...] (HOLLOWAY, 1984, p. 228).

Nos anos que se seguiram o aumento das propriedades rurais em mãos de imigrantes cresceu consideravelmente. A taxa de crescimento, por exemplo, entre os grupos de origem italiana, portuguesa e espanhola, eram superiores a 100 por centro, segundo dados de Holloway (1984, p. 229).

$\mathrm{E}$ foi nas fazendas, graças à participação dos imigrantes, que o processo de transformação teve grande impulso. Segundo Dean (1977, p. 154155) a modificação do sistema de trabalho nas fazendas ocasionou uma diversificação na economia do Estado. A demanda de consumidores aumentava, e uma maior variedade de produtos se fazia necessária, as importações já não davam conta de sustentar esse crescente mercado; é neste ponto que muitos "[...] imigrantes abandonaram o trabalho agrícola e se dedicaram a ofícios. Pequenas indústrias se multiplicaram no interior de São Paulo [...]". O autor (DEAN, 1977, p.155) destaca como exemplo a cidade de Rio Claro, que se industrializou notavelmente, contribuindo entre outros fatores o favorecimento que sua posição ferroviária lhe conferia.

Voltando nossa atenção para o meio urbano, a inserção do imigrante como importante agente no desenvolvimento econômico encontra ainda mais subsídios que merecem nossa atenção. Dean (1971, p. 58) fornece uma interessante visão sobre a inserção do imigrante como comerciante no meio urbano: “[...] A razão mais óbvia da preponderância de imigrantes no comércio, muito embora explique a propensão deles para a manufatura, é a ausência quase completa de um quadro de paulistas nativos com um estilo urbano de vida [...]".

Outros fatores que contribuíram para a inserção ainda maior de imigrantes como futuros homens de negócios foram as redes de relacionamento entre eles. Assim, aqueles que já estavam inseridos como homens bem sucedidos: "[...] os empresários tendiam a contratar ou ajudar pessoas oriundas de seus próprios países ou até vindos das mesmas cidades da Europa [...]" (DEAN, 1971, p. 61). As companhias europeias também viam nos imigrantes importantes instrumentos para o desenvolvimento das suas firmas. Desse modo, uma rede de confiança parecia legitimar esse apoio que conferiam a eles, sendo que "[...] alguns treinados pelas própri- 
as companhias, passaram a vendedores ou técnicos, outros tinham tido contatos comerciais ou sociais anteriores. Considerações políticas, quando não sentimentos nacionalistas, aconselhavam o emprego de compatriotas [...]" (1971 p. 64-65).

Mesmo o caso de um dos maiores imigrantes-empresários, o do futuro Conde Francisco Matarazzo, contou com a ajuda de outros imigrantes em seu início em Sorocaba. Matarazzo constituiu uma das maiores fortunas de sua época; para cá trouxe além da família, conhecimento e certo pecúlio (dinheiro) e, "[...] amparado por outros comerciantes italianos, abriu pequena casa de comércio [...] os negociantes seus amigos lhe forneciam capital e ele principiou a derreter banha [...]" (DEAN, 1971, p. 69). No final do século XIX, o grande empreendedor mudou-se para a capital e lá seus negócios expandiram-se, tornando-o, como já frisamos um dos empresários mais bem sucedidos de sua época.

Existiam ainda casos de imigrantes que contavam não apenas com a rede de relações com seus conterrâneos. Alguns como é o caso de Alexandre Siciliano, Italiano que chegou a São Paulo em 1869, e que mais tarde veio a residir e iniciar empreendimentos em Piracicaba. Além das relações com outros imigrantes, Siciliano também contou com ascendência sobre fazendeiros da região, fruto de sua união com uma filha de um importante e rico fazendeiro. Em companhia de um irmão e de outro sócio produziu uma máquina de beneficiar café, o projeto deu certo e a empresa prosperou, mudou-se, então, para a capital e participou de muitos outros empreendimentos rentáveis na capital e em Jundiaí (DEAN, 1971, p. 83).

Se por um lado, possuir uma rede de relações e, algum capital ajudava em muito no sucesso dos imigrantes, que vieram a se constituir em empresários; vale destacar que possuir algum capital não era uma condição essencial para que o imigrante viesse a se tornar um empresário, um homem de negócios. Tal fato pode ser mais claramente percebido quando tomamos os exemplos descritos por Barbosa (2006), em seu trabalho sobre a constituição do empresariado fabril da indústria calçadista da cidade de Franca no interior paulista.

Segundo o autor (BARBOSA, 2006, p.92), das 65 empresas registradas na cidade entre os anos de 1900 a 1945, mais da metade (36 delas, ou 55\%) eram de empresários imigrantes de origem italiana. Ao citar nomes de imigrantes ligados a essas indústrias (como Pedro Spessoto, João Palermo, Salvador Mazzota, entre outros), o pesquisador faz uma interessante observação: “[...] estes e os de procedência espanhola, segunda comunidade estrangeira mais importante, eram todos homens de origem 
modesta [...]" (2006, p. 92). A procedência humilde desses homens não atrapalhou sua inserção na nascente indústria de Franca. $\mathrm{Na}$ verdade, o fator decisivo para o seu sucesso foram os conhecimentos adquiridos para a instalação de pequenas oficinas e comércios, que como bem citou Dean (1971), não eram características do incipiente espaço urbano paulista.

A produção manufatureira possibilitou, segundo Barbosa (2006, p. 105), a sobrevivência do saber e da habilidade como elementos importantes para a produção; o que, segundo ele, barateou o início do processo de industrialização em Franca. O que de fato possibilitou um maior acesso de imigrantes-empresários de origem humilde: "[...] nesse sentido, entendemos que o ofício, a habilidade manual, possa ser interpretado como uma porta de acesso ao 'mundo empresarial' e que a capacidade criativa constitua um aspecto relevante a explicar o êxito de empresários do setor [...]".

A região de Araraquara/São Carlos também contou com a participação de imigrantes como empresários e donos de propriedades. Truzzi (2000, p. 118), ao fazer uma análise sobre o desenvolvimento das indústrias nessa região, sinaliza que o início das atividades industriais ainda estava ligado aos cafeicultores; por isso, voltadas para a produção cafeeira, como é o caso da indústria de beneficiamento de café. No entanto, mesmo este segmento, aos poucos, foi sendo explorado pelos imigrantes, como bem exemplifica o autor, citando um caso na cidade de São Carlos: "[...] em 1915, o maior estabelecimento comercial do gênero era o Engenho Victoria, de propriedade de Alexandre Masci, imigrante italiano [...]".

Quando investiga a participação dos imigrantes no desenvolvimento da indústria em São Carlos, Truzzi (2000, p. 120) destaca que esse grupo ocupa posição de protagonista em qualquer ofício. Contudo, sobressai-se em dois tipos particulares de subindústrias: a de artigos de consumo popular e a fornecedora de produtos agrícolas, mesmo com a resistência de alguns. Essa indústria de "fundo de quintal", tinha "[...] certo mercado garantido por saber tanto se aproveitar da disponibilidade de certas matérias-primas locais [...] quanto selecionar para a manufatura artigos cuja relação peso ou volume tornam-se desvantajosa a importação [...]".

Com o passar dos anos, surgiram novos setores, que foram sendo ocupados por imigrantes-empresários. Alguns já de maior expressão econômica, como é o caso da Serraria Santa Rosa, fundada por um imigrante português que, no ano de 1915, talvez fosse o maior estabelecimento industrial de São Carlos. Fato que pode ser comprovado pela serraria fornecer madeiras para a cidade, fazendas e também para as companhias ferroviárias. Além disso, a mesma contava com “[...] 400 juntas bois empregadas na 
tarefa de puxar madeira do mato em direção a algum ramal ferroviário. Para tal dispunha de 100 peões que trabalhavam nos campos com as juntas e outros 60 operários internos na própria serraria [...]" (TRUZZI, 2000 , p. 121). Outras fábricas que possuíam volume representativo em São Carlos, no início do século XX, foram: as Indústrias Giometti, responsáveis pela fabricação de peneiras, rastelos, arames e pregos; e as indústrias Facchina, que produziam adubos orgânicos, ambas as fábricas pertenciam a imigrantes de origem italiana.

Rio Claro e Araraquara também possuem muitos casos de imigrantes que se destacaram como homens de negócios. Vale ressaltar, no entanto, que no caso de Rio Claro, a cidade tinha uma situação privilegiada por ser um ponto de cruzamento entre as Companhias Paulista a Linha de Rio Claro (de bitola estreita). No início do século XX, a cidade contava com "[...] oficinas de construção de carruagem, selarias, serrarias, olarias, fornos de cal, uma fábrica de sapatos, tipografias, oficinas mecânicas. Estabelecimentos menores fabricavam massa, sabão, vinagre, colchões, chapéus de palha, charutos, foguetes e gelo [...]" (DEAN, 1977, p. 155). Mais da metade desses estabelecimentos pertenciam a imigrantes.

Caso interessante de um imigrante que se tornou importante empreendedor na cidade de Rio Claro é o de Luiz Piccoli. Segundo Dean (1977, p.180), Piccoli chegou a Rio Claro como colono, no entanto, logo se mudou para a cidade, pois considerava que o trabalho na fazenda não fornecia condições, segundo ele [Piccoli] para "se ficar rico". Esse imigrante progrediu realmente na cidade, comerciou com café e chegou a ter sete fazendas.

Com resultado da importância dos imigrantes em Rio Claro, Dean (1977, p. 182) sinaliza: "[...] Herdeira do município foi a classe média urbana, constituída de uns poucos antigos colonos; mas, na maioria, de imigrantes que na Europa tinham vivido em cidades, e tinham chegado com uma ocupação, um capital e relações familiares [...]".

No tocante a Araraquara, Corrêa (2008, p. 100 - 101) traz uma importante contribuição, quando investiga as famílias que, durante a segunda metade do século XIX, contribuíram de maneira efetiva para o desenvolvimento da localidade. Dentre elas vale destacar: os Borbas, descendentes de Joaquim Mariano Borba, comerciante que possuía armazém de secos e molhados em São Paulo, seu filho Cândido Mariano Borba, montou uma loja de fazendas e mais tarde tornou-se proprietário; os Soares de Arruda, que descendiam de Jesuíno Soares de Arruda, descendente de comerciantes portugueses, adquiriu fazenda em Piracicaba, montou comér- 
cio em Araraquara e São Carlos, adquirindo ainda fazenda em Furnas; por último, os Carvalhos, descendentes de Gabriel Antonio de Carvalho, natural de Lisboa, foi mascate e pequeno proprietário rural, no entanto, seu filho e neto acabam por destacar-se tanto como proprietários rurais, assim como líderes políticos da época.

O vínculo das famílias citadas com as propriedades rurais e com o comércio constituiu um processo de idas e vindas, o que já prenuncia que seu caráter empreendedor vai ao encontro da fala de Fernandes (2010), quando se refere a alguns grupos de fazendeiros e imigrantes contribuírem para o surgimento de uma Revolução Burguesa.

Corrêa $(2008$, p.111) chega inclusive a identificar essa característica. Para a autora existia uma parcela de investidores de pequeno capital que julgavam arriscado aplicar seu dinheiro em uma empresa tão incerta como a agrária, dedicando-se assim à atividade comercial: "[...] Tornou-se frequente a abertura de lojas de fazendas, de armarinhos e armazéns de duração efêmera, até que se completasse o capital necessário para a compra de uma terra [...]". Correia (ano, p. 111) ressalta ainda que a compra da fazenda era condição necessária para a consolidação do capital e para a conquista do prestígio social.

Voltando nossa atenção para os imigrantes, na cidade de Araraquara, imigrantes de origem humilde transformaram-se em empresários de grande prestígio, como é o caso de Henrique Lupo. De origem italiana, Lupo chegou ao Brasil com os pais e inicialmente se dedicou ao ramo de relojoeiro; mas, na década de 1920, alcançou grande destaque no cenário industrial, ao iniciar de forma ainda simples, uma pequena fábrica destinada à produção de meias. Com o passar dos anos, a pequena fábrica prosperou e ainda hoje mantém de forma reconhecida suas atividades. Outros dados estatísticos mostram o quanto os imigrantes estiveram presentes em Araraquara: "[...] Numa relação de 48 pedidos de instalação de estabelecimentos industriais no período de 1910 a 1929, apenas seis eram brasileiros; 27 eram italianos e os restantes, espanhóis, turcos e poloneses [...]" (CORRÊA, 1967, p. 302).

Uma última observação, que ratifica a importância dos imigrantes como homens de negócios, principalmente no setor industrial, pode ser percebido quando nos deparamos com a crise de 1929 e que teve reflexos durante a década de 1930. Para os cafeicultores, a crise representou inúmeras perdas econômicas e políticas, já para as indústrias, principalmente da região de São Carlos e Araraquara: 
[...] as empresas de menor porte tenham encontrado dificuldades mais agudas no trato da concorrência imposta por empresas de fora. Contudo, nenhum dos estabelecimentos mais importantes [...] teve de cerrar suas portas em função de apuros advindos de uma concorrência mais intensa [...]. (TRUZZI, 2000, p. 132).

\section{CONSIDERAÇÕES FINAIS}

O papel dos empreendedores, sejam eles imigrantes ou cafeicultores, é crucial para a investigação aqui proposta, que vai ao encontro das questões levantadas por Fernando Henrique Cardoso (1972), ao analisar o desenvolvimento e o tipo particular assumido pelas sociedades industriais e também por Fernandes (2010), ao analisar o imigrante como homem de negócios, como retomaremos nestas considerações.

A primeira questão levantada por Cardoso (1972, p. 78) está na determinação de como "[...] no interior de uma sociedade subdesenvolvida, baseada na produção agrária de mercadorias coloniais de exportação, surgiram aspirações, motivos e tipos de ação capazes de dinamizar a sociedade tradicional [...]". Já sua segundo questionamento, aponta para quais formas o processo de desenvolvimento assumiu, "[...] para verificar se as aspirações motivações e objetivos dos grupos sociais em movimento coincidiram com o padrão estrutural de desenvolvimento finalmente alcançado [...]".

Partimos das duas posições de Cardoso, para reafirmar a importância do imigrante para o desenvolvimento da economia nacional. Posição sempre lembrada por diversos autores, até mesmo por aqueles que apontam os cafeicultores como sendo os grandes incentivadores do desenvolvimento comercial e industrial do Brasil.

Críticos sempre dedicaram considerações sobre a participação dos imigrantes dentro do processo de transformações presentes no final do século XIX e início do século XX; período que marcou o auge da lavoura cafeeira e, por isso, o predomínio dos barões do café nas esferas política, social e econômica. No entanto, autores como Florestan Fernandes (2010) veem no imigrante um personagem decisivo para as transformações que levaram ao desenvolvimento de uma revolução burguesa no Brasil.

A revolução burguesa foi o ponto de partida deste primeiro capítulo, cuja temática foi a do imigrante como homem de negócios no interior paulista. Por meio das características levantadas e das considerações de Florestan (2010), a linha de raciocínio, que tratou o imigrante como empresário em potencial, ou como homem de negócios, ganhou significado. Lógico que não podemos descartar a participação dos cafeicultores dentro 
deste processo, eles contribuíram para o seu início, mudaram sua visão e constituíram, por assim dizer, também um espírito empreendedor. Além disso, foram também homens de negócios. Mas o próprio Florestan (2010) , assim como autores que trabalharam a esfera mais regional e local do interior paulista, como Truzzi (2000) e Barbosa (2006), detectam que essa postura, essa visão diferenciada não é uma característica que engloba um grupo muito grande de cafeicultores, na verdade destacam que este grupo é até reduzido.

O imigrante é tratado por Florestan Fernandes (2010) como um herói dentro do processo de desenvolvimento da revolução burguesa no Brasil. Para isso, uma série de fatores contribuem, como o fato de alguns já trazerem consigo certo pecúlio (capital), ou certo conhecimento, ou ainda uma rede de relações, enfim estes e outros fatores não são autoexcludentes. $\mathrm{Na}$ verdade, muitas vezes, eles trabalhavam em conjunto para aumentar as chances de sucesso do imigrante como futuro homem de negócios. Chama a atenção ainda que mesmo os mais humildes, acabaram constituindo negócios modestos, e que dependendo da localidade e do ramo, viram frutificar esses negócios.

Cabem ainda duas considerações que ajudam a ratificar a linha de raciocínio tanto do trabalho de Florestan Fernandes (2010), quando deste pequeno texto. Fernandes (2010, p.174) frisa que tanto os fazendeiros, quanto os imigrantes, como sendo agentes humanos desse processo, a diferença está na postura, na visão de cada um deles "[...] O fazendeiro tinha um pé no presente, outro no passado. $\mathrm{O}$ imigrante, ao contrário, tinha um pé no presente, outro no futuro [...]".

Lógico que existiam autores como Sérgio Silva (1986), Wilson Cano (1998) e João Manuel Cardoso de Mello (1998), que analisam o desenvolvimento industrial a partir da binômio café/indústria, e por isso destacam as muitas contribuições dos fazendeiros para o desenvolvimento industrial.

\footnotetext{
A economia cafeeira capitalista cria, portanto, as condições básicas ao nascimento do capital industrial e da grande indústria ao: 1) gerar, previamente uma massa de capital monetário, concentrada nas mãos de determinada classe social, passível de se transformar em capital produtivo industrial; 2) transformar a própria força de trabalho em mercadoria; e, finalmente, 3) promover a criação de um mercado interno de proporções consideráveis (MELLO, 1982, p. 99)
}

Ao abordar a participação efetiva dos fazendeiros de café no processo de industrialização, Martins (2010, p. 227) observa que realmente não 
foram muitos aqueles que se dedicaram às atividades industriais no período classificado por ele como de gênese da indústria em São Paulo (de 1870 a 1905). Em parte ele aponta que isto era devido ao caráter intersticial da indústria e das incertezas decorrentes no processo, no entanto, conclui também que aqueles que estiveram presentes no processo tornaram-se acionistas e diretores de empresas, em especial bancos e ferrovias, em consequência disto estiveram envolvidos no processo tipicamente empresarial de tomada de decisões nos negócios.

Dentro deste novo cenário, vemos a passagem de uma sociedade de base agrária exportadora, marcada pela dependência política, para uma nova industrial e autônoma, que rendeu ao Brasil uma rearticulação em seu sistema de poder e uma nova postura nas relações de negociação com 0 mercado externo. (CARDOSO, 1972, p. 85).

O leque de opções, para se trabalhar a questão do imigrante como homem de negócios e/ou empreendedor no interior paulista, assim como em outras localidades brasileiras, é muito grande. Por esse motivo, elegemos para este dissertação trabalho o interior paulista, particularmente a região de São Carlos, no período entre o final do século XIX e as primeiras décadas do século XX, no intuito de compreender a formação e o desenvolvimento do empresariado local. Este trabalho investigativo também pode motivar novos estudos em outras regiões.

\section{REFEREANCIAS BIBLIOGRAFICAS}

Almanache álbum de São Carlos - 1894, 1905, 1915, 1916/1917, 1927 e 1928.

BARBOSA, Aguinaldo de Sousa. Empresariado Fabril e Desenvolvimento Econômico. São Paulo, Editora Hucitec. 2006.

BRANDÃO, I. de L.; TELAROLLI, R. Adio Bel Campanile - A Saga dos Lupos. São Paulo, Global Editora. 1998.

CARDOSO, Fernando Henrique. Mudanças sociais na América Latina. São Paulo, Difel, 1969.

, Fernando Henrique. Empresário industrial e desenvolvimento econômico no Brasil. São Paulo, Difusão européia do livro, 1972.

CANO, W. Raízes da concentração industrial em São Paulo. 2a edição, São Paulo, T.A. Queiroz, 1981. CORRÊA. A.M.M. História social de Araraquara 1817 a 1930. São Paulo, FFLCR, Universidade de São Paulo. (Dissertação de Mestrado). 1967.

A.M.M. Araraquara - 1720 - 1930: Um capítulo da história do café em São Paulo.São Paulo, Cultura acadêmica. 2008.

DEAN, Warren. A industrialização de São Paulo, São Paulo, Difel, 1971.

Warren. Rio Claro: um sistema de grande lavoura 1820 - 1920. Trad. de Waldívia Portinho. Rio de Janeiro, Paz e Terra, 1977. 
FERNANDES, Florestan. A revolução burguesa no Brasil - ensaio de interpretação sociologia. $5^{\text {a }}$ edição, $4^{\text {a }}$ reimpressão, São Paulo, Editora Globo, 2010.

HOLLOWAY, T.. Imigrantes para o café. São Paulo: Paz e Terra, 1984.

MARTINS, José de Souza. Conde Matarazzo: O empresário e a empresa. 2a edição. São Paulo: Hucitec, 1974.

José de Souza. O cativeiro da terra. São Paulo: Ciências Humanas. 2010.

MELLO, João Manuel Cardoso de. O capitalismo tardio. São Paulo, Brasiliense, 1998.

SALLUM JUNIOR, Basílio. Capitalismo e cafeiculura - Oeste-Paulista: 1888 - 1930. São Paulo, Livraria Duas Cidades. 1982.

TRUZZI, Oswaldo Mário Serra. Café e Indústria São Carlos: 1850 - 1950. São Carlos: Editora da UFSCar, 2000. 